Properties.-White prisms from dilute alcohol, which did not melt even at $280^{\circ}$. It is soluble in alcohol; slightly soluble in ether; essentially insoluble in water, chloroform, acetone, glacial acetic acid, naphtha, or benzene.

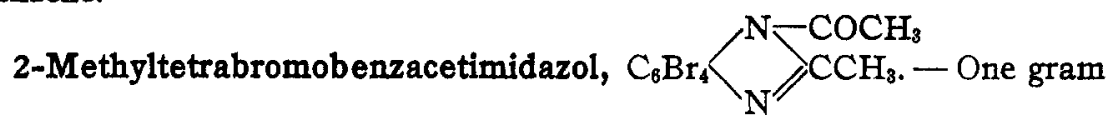
of tetrabromo-o-phenylenediacetamid was boiled under a return condenser with equal parts of sulfuric acid and water for 4 hours, when upon adding sodium hydroxide to the solution a precipitate was thrown down, which after 3 crystallizations from dilute alcohol melted constant at $265^{-2}-266^{\circ}$ (uncorr.). The same product was obtained, when $0.5 \mathrm{~g}$. of the diacetamid was heated for 4 hours in a sealed tube with alcoholic ammonia. After evaporating off the solvent, and recrystallization from dilute alcohol, the melting point was $265^{\circ}$ (uncorr.). Upon boiling some of the diacetamid for 2 hours with a solution of sodium hydroxide, diluting with water, and extracting with ether, a product was obtained, whose melting point in the crude state showed it was identical with the other two.

Subs, o.1077, 0.1207. AgBr, 0.1646, 0.1848. Calc. for $\mathrm{C}_{10} \mathrm{H}_{6} \mathrm{Br}_{4} \mathrm{~N}_{2} \mathrm{O}: \mathrm{Br}, 65.30$. Found: $\mathrm{Br}, 65.03,65.18$.

Properties.-White crystals melting at $265^{-266^{\circ}}$ (uncorr.). It is soluble in all the common organic solvents, but insoluble in water.

Cambridge, Mass.

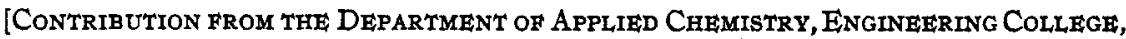
IMPERIAL UNIVERSITY OF JAPAN.]

\title{
THE ESSENTIAL OIL OF SUGI (Cryptomeria japonica) LEAVES.
} BY So Ucrids.

Received December 8, 1915.

The Sugi (Cryptomeria japonica, Don.) is a coniferous tree, indigenous to Japan, and is extensively cultivated throughout the whole empire as a valuable timber tree. The wood is most widely used and prized as a timber wood and for general woodwork. The stems, leaves and roots contain essential oil. No study, as far as I know, has hitherto been made of the oil contained in the leaves.

The green leaves of Sugi, weighing $87.4 \mathrm{~kg}$., on distillation with steam, yielded $6 \mathrm{r} 2 \mathrm{~g}$. of volatile oil, which is equivalent to $0.70 \%$. The oil is mobile, brownish yellow in color and has a fresh aromatic odor. When the oil was cooled to $-5^{\circ}$ for an hour in a mixture of ice and salt, no solid substance separated. A small amount of the oil was distilled in a flask under atmospheric pressure; it began to boil at about $155^{\circ}$ and continued to distil until the thermometer reached $35^{\circ}$, the following fractions being obtained: $155-190^{\circ} 33 \%, 190-230^{\circ} 4 \%, 230-270^{\circ} 4 \%, 270-$ 
$310^{\circ} 28 \%, 310-350^{\circ} 23 \%$. When bromine was added drop by drop, the oil combined violently with it, evolving a large amount of heat and changed to a greenish, viscous oil. Two drops of the oil were dissolved in I cc. of acetic anhydride and then shaken with a drop of concentrated sulfuric acid. The liquid assumed an intense green color and became very viscous. When a few drops of the oil were added to 2 cc. of concentrated sulfuric acid, the oil dissolved in it, assuming a yellowish brown color, and slowly a small amount of thick reddish brown oil formed on the surface of the liquid. The oil does not give any characteristic color reaction with very dilute ferric chloride solution. It does not reduce ammoniacal silver oxide, and contains neither nitrogen nor sulfur. The oil is completely soluble in the usual organic solvents and furnishes the following constants:

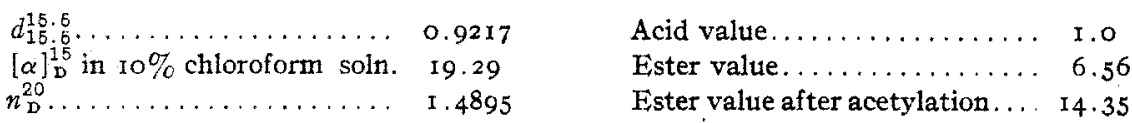

The total amount of the oil employed for the investigation was $454 \mathrm{~g}$.

Treatment with Sodium Carbonate.-In order to separate any uncombined acids, the oil was three times successively extracted with a $5 \%$ solution of sodium carbonate. The combined alkaline liquid of brownish yellow color was shaken with ether four times. The ethereal solution, after evaporating off the ether, was added to the main part of the oil. The alkaline water solution was then acidified with sulfuric acid and extracted thoroughly with ether. The ethereal liquid, thus obtained, was washed with water and dried with anhydrous sodium sulfate. On evaporating off the ether, there remained a yellowish, very viscous oil having an odor of higher fatty acids, but its amount was too small to admit of further examination.

Fractional Distillation of the Oil.- The oil, shaken with dilute sodium carbonate solution, was washed with water successively until the wash water was neutral to litmus and then dried with anhydrous sodium sulfate. It was subsequently subjected to fractional distillation under $15 \mathrm{~mm}$. pressure, a current of carbon dioxide being passed into the liquid to insure regular ebullition, and was resolved into the following three fractions:

\begin{tabular}{|c|c|}
\hline I. & $50-100^{\circ}$ \\
\hline II. & $100-180^{\circ}$ \\
\hline III. & $180-200^{\circ}$ \\
\hline
\end{tabular}

Identification of $\alpha$-Pinene.-Fraction I (b. p. $50-100^{\circ}$ under I $5 \mathrm{~mm}$. pressure). This fraction, representing in fact nearly one-third of the whole of the oil employed, was a mobile, colorless liquid and had a somewhat lemon-like odor. When heated with a small piece of sodium, it was found to be practically unacted on. The oil, after purifying by repeated distillation over sodium under $50 \mathrm{~mm}$. pressure, was finally dis- 
tilled under atmospheric pressure and was resolved into the following three fractions:

$$
(a), 158-163^{\circ} ;(b), 163^{-168^{\circ}} ;(c), 168-172^{\circ} .
$$

Fraction $158-163^{\circ}$. The greatest portion of this fraction, on redistillation, boiled at $161-162^{\circ}$. It was colorless and mobile and possessed a turpentine-like odor. It had a specific gravity of 0.8567 at $15.5 / 15.5$ and $n_{\mathrm{D}}^{20}=\mathrm{I} .4666$. It is optically active and rotates the plane of polarization to the right in a $100 \mathrm{~mm}$. tube by $2^{\circ} 30^{\prime}$.

Preparation of Nitrosochloride.-The nitrosochloride was made by a slightly modified method of Wallach. ${ }^{1}$ A white, lamellar, crystalline substance separated, which was collected, washed with cold alcohol and finally purified by precipitating with methyl alcohol from its chloroform solution. The crystals, thus purified, melted at $\mathrm{IO}^{-104^{\circ}}$ to a brownish black liquid.

Preparation of Nitrolpiperidine and Nitrolbenzylamine.-When the nitrosochloride was heated on the water bath with an excess of piperidine in alcoholic solution, a vigorous action occurred resulting in the formation of nitrolpiperide, and the liquid assumed a pale yellowish green color. After cooling, sufficient water was added and an oily substance of yellowish brown color precipitated, which solidified to a crystalline mass on standing overnight. When purified by several recrystallizations from a mixture of ether and alcohol, it melted constant at I I $8-$ II $^{\circ}$.

A nitrolbenzylamine was also prepared from the nitrosochloride by a similar method. After recrystallization, it melted constant at I22$123^{\circ}$. Thus the identification of this fraction with $\alpha$-pinene was established.

Fraction $163^{-168^{\circ}}$. This has a density $d_{15.5}^{15.5}=0.8570$ and $[\alpha]_{D}^{15}=$ $17.37^{\circ}$ in a $100 \mathrm{~mm}$. tube. The index of refraction is $n_{\mathrm{D}}^{15}=1.4679$. It was a colorless, mobile liquid, having a pleasant odor. This fraction was specially tested for $\beta$-pinene but with a negative result.

Fraction $168-172^{\circ}$. This fraction was a colorless, mobile liquid having a pleasant odor and was relatively small in amount. The liquid when examined in a tube $100 \mathrm{~mm}$. long, at $20^{\circ}$, produced a rotation $24.8 \mathrm{I}^{\circ}$ to the right. A density' determination gave $d_{15.5}^{15.5}=0.8778$ and the index of refraction was $n_{\mathrm{D}}^{20}=1.4736$.

Preparation of Dibromide.-To detect the presence of limonene or dipentene in this fraction, bromine was added drop by drop in a well-cooled solution of the fraction in glacial acetic acid. The color disappeared at first and did not become permanent until two atoms of bromine had been added for every molecule of the compound. Since nothing had separated from the solution even after two days, the product was precipitated by the addition of water and taken up with ether. The ethereal

${ }^{1}$ Ann., 245, 24I (1888). 
solution was washed with solution of sodium carbonate and afterwards with water and dried with anhydrous sodium sulfate. After evaporating off the ether, the residue was kept in a vacuum over paraffin for several weeks. Bromine was estimated by Carius's method.

0.2822 g. gave $0.3664 \mathrm{~g} . \mathrm{AgBr} . \mathrm{Br}=55.25 \% . \quad \mathrm{C}_{10} \mathrm{H}_{18} \mathrm{Br}_{2}$ requires $\mathrm{Br}=54.00 \%$.

Thus the fraction was dibromic and the absence of limonene or dipentene was confirmed. A careful search was also made for terpinene, sylvestrene, phellandrene and cineol in this fraction, but none of them was detected.

The presence of $\alpha$-pinene in these preceding two fractions was also confirmed by means of the nitrosochloride, nitrolpiperidine and nitrolbenzylamine. The low-boiling fraction of Sugi leaves oil, therefore, consists chiefly of $\alpha$-pinene.

Hydrolysis of Fraction II.--In order to hydrolyze the ester, Fraction II, boiling between 100 and $180^{\circ}$ under I $5 \mathrm{~mm}$. pressure, was boiled for three hours with alcoholic potash in a flask connected with a reflux condenser. After the greater part of alcohol had been removed by distillation, the liquid was transferred to a separating funnel and a sufficient quantity of sodium chloride solution was added to effect the separation of the oil. The aqueous alkaline liquid separated from the oil was shaken with successive portions of ether to remove the last trace of oil. The aqueous alkaline liquid thus extracted with ether was set aside for the examination of the acids. The ethereal extract was mixed with the separated oil, washed with water four times successively and dried with anhydrous sodium sulfate. After distilling off the ether, the oil was fractionally distilled twice under atmospheric pressure and was resolved into the following four fractions:

$$
\text { (a), } 195^{-235^{\circ}} \text {; (b), } 235^{-280^{\circ}} \text {; (c), } 280-310^{\circ} \text {; (d), } 310-330^{\circ} \text {. }
$$

Fraction $195^{-235^{\circ}}$. This fraction was relatively small in amount, representing $7 \%$ of the whole of the oil investigated and was freely soluble in $70 \%$ alcohol. It was distilled under atmospheric pressure, coming over mainly at $212-214^{\circ}$. The two chief fractions, boiling at $185^{-205^{\circ}}$ and $205^{-220^{\circ}}$, were collected.

Identification of Dipentene.-Fraction I $85^{-205^{\circ}}$, which evidently contained terpenes, was distilled over metallic sodium under atmospheric pressure and the following three fractions were obtained: $168-172^{\circ}$, $172^{-1} 75^{\circ}, 175^{-1} 78^{\circ}$, weighing $2.28 \mathrm{~g} ., 2.35 \mathrm{~g}$, and $\mathrm{I} .90 \mathrm{~g}$., respectively.

To detect the presence of limonene or dipentene in these fractions, bromine was added drop by drop to their well-cooled solutions in glacial acetic acid until the color of bromine remained permanent.

$\begin{array}{cccc}\text { Fractious. } & \text { Weight of oil. } & \text { Bromine used. } & \text { Percentage of Br. } \\ 168-172^{\circ} & 2.28 \mathrm{~g} . & 1.08 \mathrm{cc} .=3.44 \mathrm{~g} . & 15 \mathrm{I} \% \\ 172-175^{\circ} & 2.3 \mathrm{Ig} . & 1.04 \mathrm{cc} .=3.31 \mathrm{~g} . & 143 \% \\ 175-178^{\circ} & 1.90 \mathrm{~g} . & 0.97 \mathrm{cc} .=3.09 \mathrm{~g} . & 163 \%\end{array}$

Dibromic $\mathrm{C}_{10} \mathrm{H}_{16}$ requires $117.7 \% \mathrm{Br}$. Tetrabromic $\mathrm{C}_{10} \mathrm{H}_{16}$ requires $235.3 \% \mathrm{Br}$. 
It is obvious from the result of the experiments that these fractions contain a considerable amount of a tetrabromic terpene. After standing for 4 days, they became brownish black liquids and only Fraction 175${ }_{17} 8^{\circ}$ deposited an exceedingly small amount of white crystals. These were collected, drained on a porous tile and recrystallized three times from acetic ether. The product melted at $123-124^{\circ}$. Thus the presence of dipentene in this fraction was confirmed.

Alcohol.-Fraction $205^{-220^{\circ}}$, obtained as above described, was then redistilled. The main portion passed over between 210 and $215^{\circ}$, and especially between the limits $212-214^{\circ}$. This fraction $\left(212-214^{\circ}\right)$ was a faint yellow, mobile liquid possessing a powerful fresh odor recalling that of camphor and peppermint at the same time. When cooled to $-15^{\circ}$, it did not show any tendency to crystallize, even after a lapse of several hours.

$$
\begin{aligned}
& 0.2557 \mathrm{~g} \text {. gave } 0.7348 \mathrm{CO}_{2} \text { and } 0.2792 \mathrm{H}_{2} \mathrm{O} \ldots \ldots \ldots, \mathrm{C}=78.35 \quad \mathrm{H}=12.13 \\
& \mathrm{C}_{10} \mathrm{H}_{18} \mathrm{O} \text { requires...................... } \mathrm{C}=7 \mathbf{7 7 . 8 5} \quad \mathrm{H}=\mathrm{II} .77
\end{aligned}
$$

$0.5727 \mathrm{~g}$. dissolved in $19.076 \mathrm{~g}$. benzene caused a depression of the freezing point of $0.923^{\circ}$. Hence the molecular weight $=162.7, \quad \mathrm{C}_{10} \mathrm{H}_{18} \mathrm{O}$ requires I54.I.

It does not reduce ammoniacal silver oxide. It has a density $d_{18}^{18}=$ 0.9414 and produced a rotation $[\alpha]_{D}=+56.07^{\circ}$ in $8.98 \%$ chloroform solution. The refractive index is $n_{D}^{18}=I .4832, M . R .=46.80$.

Acetylation Experiment.-The oil was boiled for two hours with acetic acid anhydride in the presence of anhydrous sodium acetate, and then a sufficient quantity of water was added and it was heated for two hours on a water bath. The product was repeatedly extracted with ether and the ethereal solution was washed first with dilute sodium carbonate solution and then with water and dried with anhydrous sodium sulfate. On evaporating off the ether a pale yellow, mobile liquid having an aromatic odor was obtained.

The acetylated oil was saponified with $0.5 \mathrm{~N}$ alcoholic potash and the excess of potassium hydroxide was titrated with sulfuric acid. r.5016 g. acetylated oil required for saponification $0.2146 \mathrm{~g}$. $\mathrm{KOH}$. For an acetic ester of the formulae $\mathrm{C}_{10} \mathrm{H}_{17} \mathrm{O} . \mathrm{COCH}_{8}, 0.4295 \mathrm{~g}$. $\mathrm{KOH}$ would be required. From this result it will be seen that this alcohol cannot be entirely converted into its acetic ester, perhaps due to the partial decomposition during the operation as in the case of linalöol.

Oxidation with Bichromate and Permanganate.-This fraction was then oxidized with chromic acid mixture and after reducing the excess of bichromate, the product was distilled with steam. The distillate was made alkaline by potassium carbonate and extracted thoroughly with ether and the ethereal liquid was washed, dried and evaporated. The brownish yellow, mobile oil, thus obtained, possessed a high aromatic 
odor and did not reduce ammoniacal silver oxide. On combustion, it was found to consist of $\mathrm{C}=70.41 \%, \mathrm{H}=12.44 \%, \mathrm{O}=17.15 \%$.

Oxidations with permanganate at ordinary and at ice-cold temperature were also made, but no characterized products were obtained.

This alcohol, though existing in small amount, has evidently a considerable influence on the odor of the original oil and it can be regarded as the chief odorous constituent of the oil.

Sesquiterpenes.-Fraction $235^{-280^{\circ}}$. This fraction, representing about $22 \%$ of the oil employed, was a yellowish green, viscous oil and was sparingly soluble in $70 \%$ alcohol. It was found to give only a slight action with sodium and hence consisted almost entirely of hydrocarbons. The fraction was purified by repeated distillation over sodium under reduced pressure, until the metal remained bright through the whole distillation, and it was finally distilled over sodium under atmospheric pressure. Thus purified, it passed over chiefly between $260-270^{\circ}$ and smaller fractions were also collected at $250-260^{\circ}$ and $270-280^{\circ}$. Most of the oil distilled over between 266 and $268^{\circ}$. Fraction $260-270^{\circ}$ was, therefore, redistilled and a fraction boiling at $266-268^{\circ}$ was collected. On combustion, it gave the following figutes:

$$
\begin{aligned}
& 0.3497 \mathrm{~g} \text {. gave } \mathrm{I} .1233 \mathrm{CO}_{2} \text { and } 0.3593 \mathrm{H}_{2} \mathrm{O} \ldots \ldots \ldots \mathrm{C}=87.60 \quad \mathrm{H}=1 \mathrm{I} .4^{2}
\end{aligned}
$$

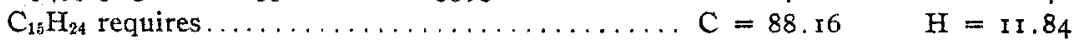

$0.3476 \mathrm{~g}$. substance in $18.523 \mathrm{~g}$. of benzene caused a depression of the freezing point of $0.449^{\circ}$. Hence the molecular weight is 209.0 . $\mathrm{C}_{10} \mathrm{H}_{24}$ requires 204.2.

This fraction, therefore, consists of a sesquiterpene. It furnished the following constants:

$$
d_{15.5}^{15.5}=0.9335, d_{22.8}^{22.8}=0.9245 .
$$

$[\alpha]_{\mathrm{D}}=+\mathrm{r} 5.19^{\circ}$ in a $6.08 \%$ chloroform solution. $\quad n_{\mathrm{D}}^{22.8}=\mathrm{r} .504 \mathrm{r}$.

The molecular refractive energy of the compound calculated by means of the formulae $n^{2}-1 / n^{2}+2 . \mathrm{M} / d$ is, therefore, 65.3 . The calculated number for $\mathrm{C}_{15} \mathrm{H}_{24}$ with two double linkings is 66.15. This evidence of the presence of two pairs of "doubly linked" carbon atoms is borne out by the analysis of the hydrochloride described below.

The liquid was viscous and almost colorless and possessed a weak hay-like odor. When a few drops of this fraction were dissolved in a few cc. of acetic acid anhydride and shaken with one drop of concentrated sulfuric acid, the liquid assumed a yellowish green color which at once became green, then blue and finally turned to a deep indigo color.

Action of Hydrogen Chloride.-Dry hydrogen chloride was passed into a well-cooled solution of Fraction $266-268^{\circ}$ in two times its volume of ether. The gas was readily absorbed and the liquid finally became brown. After saturating the liquid with hydrogen chloride, it was corked tightly and allowed to remain overnight, when the liquid turned to violet-black. This, after being washed with ice-cold water four times, was dried with 
anhydrous sodium sulfate. On evaporating off the ether under reduced pressure, a brownish black oil of very viscous nature was left, which was allowed to remain for several weeks in a vacuum over paraffin and calcium chloride. The oil, thus obtained, on being cooled to $-20^{\circ}$, became more viscous, but did not show any tendency to crystallize even after a lapse of three hours. A chlorine determination was made by Carius's method.

$0.4937 \mathrm{~g}$. gave $0.4760 \mathrm{AgCl}, \mathrm{Cl}=23.85 \% ; \mathrm{C}_{15} \mathrm{H}_{24.2} \mathrm{HCl}$ requires $\mathrm{Cl}=25.59 \%$.

Though a small discrepancy is observed between the experimental result and the theoretical value for chlorine, owing to the unstable nature of the hydrochloride, it is clear that the sesquiterpene has two double linkings. To obtain a crystalline derivative of this sesquiterpene, the preparation of a nitrosochloride, a nitrosite, a bromide, a nitrosate and a hydrate were carefully tried by the well-known methods but the results were unsatisfactory.

Identification of Cadinene.-Fraction $270-280^{\circ}$ obtained by the redistillation of Fraction $235^{-280^{\circ}}$ over sodium was relatively small in amount. In order to test for the presence of cadinene, as it is often found in essential oils, this fraction was redistilled and a fraction boiling between $272-275^{\circ}$ was collected. A hydrochloride of this fraction was prepared exactly as above described. The resulting brownish black oil of very viscous nature was kept in a vacuum over paraffin and calcium chloride for several weeks when exceedingly small quantities of minute needle crystals separated from the liquid. These were collected, drained on a porous tile and crystallized from acetic ether. The white, lustrous, needle-shaped crystals, thus obtained, melted constantly at $I I 7-I I 8^{\circ}$ to a reddish liquid suffering almost no decomposition. A chlorine determination by the Carius method gave the following result:

0.0375 g. gave $0.0385 \mathrm{AgCl}, \mathrm{Cl}=25.40 \% ; \mathrm{C}_{15} \mathrm{H}_{24.2} \mathrm{HCl}$ requires $\mathrm{Cl}=25.59 \%$.

A mixture of these crystals and cadinene hydrochloride did not show any depression of the melting point, confirming the presence of cadinene in this fraction.

Sesquiterpene Alcohol.-Fraction 280-310 . This fraction, representing about $10 \%$ of the oil employed, had a very beautiful deep blue color and was sparingly soluble in $70 \%$ alcohol. On successive redistillation under atmospheric pressure, the greater part of the oil passed over beween $280-290^{\circ}$, mainly at $284^{-286^{\circ}}$. Fraction $284^{-286^{\circ}}$, collected during the distillation, was a viscous liquid, having a beautiful deep blue color and a weak characteristic odor. On cooling to $-10^{\circ}$, it became more viscous but did not show any tendency to crystallize even after the lapse of several hours. This liquid, when dissolved in glacial acetic acid and treated with a drop of concentrated sulfuric acid, yielded a green color which turned to blue at once and finally to deep indigo. It has a density $d_{15.5}^{15.5}=$ $0.9623 ;[\alpha]_{\mathrm{D}}^{15}=16.76^{\circ}$ in a $5 \%$ chloroform solution and $n_{\mathrm{D}}^{22.8}=1.5048$. 
$0.225 \mathrm{I}$ g. gave $0.6717 \mathrm{CO}_{2}$ and $0.2319 \mathrm{H}_{2} \mathrm{O} \ldots \ldots \ldots \mathrm{C}=8 \mathrm{I} .39 \quad \mathrm{H}=\mathrm{II} .45$

$0.2162 \mathrm{~g}$. gave $0.6448 \mathrm{CO}_{2}$ and $0.2274 \mathrm{H}_{2} \mathrm{O} \ldots \ldots \ldots \mathrm{C}=8 \mathrm{I} .32 \quad \mathrm{H}=\mathrm{II} .69$

$0.267^{8} \mathrm{~g}$. gave $0.7986 \mathrm{CO}_{2}$ and $0.29 \mathrm{rg} \mathrm{H}_{2} \mathrm{O} \ldots \ldots \ldots \mathrm{C}=8 \mathrm{I} .34 \quad \mathrm{H}=\mathrm{r} 2 . \mathrm{II}$

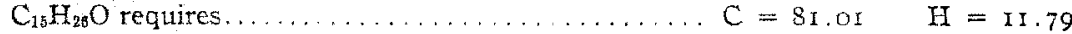

$0.3625 \mathrm{~g}$. dissolved in $19.08 \mathrm{~g}$. benzene caused a depression of the freezing point of $0.435^{\circ}$. Therefore, the molecular weight $=218.0 . \mathrm{C}_{16} \mathrm{H}_{28} \mathrm{O}$ requires 222.2.

This fraction, therefore, consists of a sesquiterpene alcohol. Several essential oils are known to afford high boiling fractions of a deep blue color for which the name "Azulene" had been proposed by Piesse and "Coerulein" by Gladstone. The compound was recently investigated by $\mathrm{A}$. $\mathrm{E}$. Sherndal ${ }^{1}$ and found to be a hydrocarbon, $\mathrm{C}_{15} \mathrm{H}_{18}$, having such a striking color intensity that $0.064 \mathrm{~g}$. dissolved in a liter of benzene matches an ammoniacal solution of copper sulfate containing $0.24 \mathrm{~g} . \mathrm{CuSO}_{4}$ to the liter in depth of color. The deep blue color of this fraction is in all probability due to the presence of a trace of a blue hydrocarbon, "Azulene," while a sesquiterpene alcohol makes up the builk of the oil.

Fraction $310^{-} 330^{\circ}$. This fraction, weighing $5 \mathrm{~g}$. or $1 \%$ of the whole of the oil used, had a deep blue color and was a very viscous oil when first distilled: But after a time it deposited a considerable amount of white, needle-like crystals which were collected, washed with glacial acetic acid and recrystallized from acetic ether. It melted accurately at $6 \mathrm{I}^{\circ}$ and was confirmed to be identical with a new diterpene consisting of the next fraction and will further be discussed later. 'The oil after separating the crystals was of deep blue color and very viscous. It gave the same color reaction as that of the preceding fraction. Thus, this fraction is apparently a mixture of the preceding and the following fraction.

A New Diterpene.-Fraction III. Fraction III (180-200 under I $5 \mathrm{~mm}$. pressure), obtained by the fractional distillation of the oil treated with sodium carbonate solution, was $75 \mathrm{~g}$. or $16.5 \%$ of the whole of the oil used. When first distilled, it was an oil of very viscous nature, possessing a yellow color, but when cooled to the room temperature it solidified to a crystalline hard mass. To separate any adhering oily substance, the total mass was poured into glacial acetic acid, drained on a porous tile, washed with cold alcohol and finally purified by recrystallization from acetic ether, from which it separated in the form of white, glistening, odorless, stellated needles Thus purified, it melted at $6 \mathrm{r}^{\circ}$.

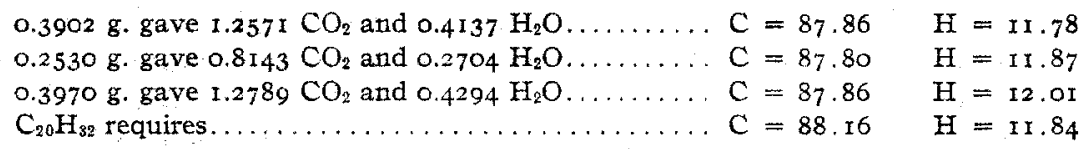

Determinations of its molecular weight, using benzene as the solvent.

I, $0.6845 \mathrm{~g}$, and II, I.2235 g., in $20.250 \mathrm{~g}$. benzene gave $0.637^{\circ}$ and $1.150^{\circ} \mathrm{de}-$ pression, $=\mathrm{M}$. W. $265 ; 263 . \mathrm{C}_{20} \mathrm{H}_{32}$ requires 272 .

1 This Journal, 37, 167, 1537 (1915). 
This substance, therefore, is a diterpene. It has a very high boiling point and boils, in fact, at $198^{\circ}$ under $15 \mathrm{~mm}$. pressure and at $345^{\circ}$ under atmospheric pressure without any decomposition. It is laevorotatory; $[\alpha]_{\mathrm{D}}^{20}=-34.32^{\circ}$ in a $4.69 \%$ chloroform solution. It is readily soluble in ether, chloroform, benzene and petroleum ether; soluble in hot acetic ether; difficultly soluble in cold acetic ether and hot alcohol and insoluble in glacial acetic ether and in cold alcohol. Thus, it is most convenient to wash with glacial acetic acid to separate any adhering oil from the crystals and to use acetic ether for recrystallization. A few drops of an ether solution of iodine were added to a solution of this diterpene in the same solvent but the color of iodine remained permanent. This indicates this crystalline diterpene to be a saturated compound. Also, this diterpene is difficultly combustible.

Action of Bromine.-On adding bromine drop by drop to this diterpene directly, no violent reaction occurred and a reddish brown resinous substance was formed which it was impossible to crystallize by any means.

Action of Sulfuric Acid. - The crystalline diterpene was added to concentrated sulfuric acid, in which it dissolved at first, assuming a yellowish orange color and a reddish orange oily substance slowly formed on the surface of the liquid. After standing overnight, the liquid was added drop by drop to a sufficient quantity of water, care being taken not to raise the temperature above $30^{\circ}$ during the operation (otherwise, sulfuric acid oxidizes the oil with evolution of sulfur dioxide), when a yellowish orange oily substance precipitated which was taken up with ether. The ethereal solution was washed with cold water until it gave no acid reaction to litmus and was then dried with anhydrous sodium sulfate. On evaporating off the solvent carefully, a pale yellow, viscous oil of somewhat petroleum-like odor was left which did not crystallize even after cooling to $-15^{\circ}$ for several hours. The oil thus obtained was allowed to remain for several weeks in a vacuum desiccator filled with paraffin to eliminate the last trace of ether. After the lapse of that time, the oil became very viscous, in fact, a semi-resinous substance. Suspecting this substance to be a sulfonic derivative of the diterpene, a determination of sulfur was made but the substance was found not to contain sulfur.

Fuming sulfuric acid reacts violently with this diterpene evolving a large amount of heat and the substance was charred.

Action of Hydrogen Chloride.-On passing dry hydrogen chloride into a well-cooled solution of this diterpene in ether, a large amount of white crystals separated and the liquid assumed a faint yellow color. The compound, after separating from the liquid, was washed with ether and recrystallized from acetic ether, from which it separated as fine, white needles having a radial aggregation. The crystals, thus purified, melted at $2 \mathrm{II}-2 \mathrm{I} 2^{\circ}$. When pressed with a glass rod, the substance gives a soft 
elastic feeling. It is difficultly soluble in ether and in cold acetic ester but soluble in hot acetic ester and in phenol. The crystals, when melted, sublime and float in the air as light feathers.

$$
\begin{aligned}
& 0.1967 \mathrm{~g} \text {. gave } 0.6342 \mathrm{CO}_{2} \text { and } 0.2 \mathrm{II} \mathrm{H}_{2} \mathrm{O} \ldots \ldots \ldots, \mathrm{C}=87.90 \quad \mathrm{H}=11.9 \mathrm{I} \\
& \mathrm{C}_{20} \mathrm{H}_{82} \text { requires....................... }
\end{aligned}
$$

This substance is, therefore, an isomer of the crystalline diterpene above described.

For the diterpene isolated by the author from Sugi leaves oil the clear evidence of its chemical individuality justifies me, I think, in proposing for it the designation of " $\alpha$-Cryptomerene" in consideration of its botanical source. The name " $\beta$-Cryptomerene" is also suggested for the crystals precipitated from the ethereal solution of " $\alpha$-Cryptomerene" by hydrogen chloride. For the sake of clearness, all known diterpenes" which have been investigated, and their properties will be given in the table below.

\section{Acids Obtained by the Hydrolysis of the Oil.}

The alkaline aqueous liquid, separated from the hydrolyzed oil and completely extracted with ether, as previously described, was acidified with sulfuric acid and distilled with steam. The first portion of the distillate was slightly turbid but it became clear after a time and about $600 \mathrm{cc}$. of the distillate were collected. A few drops of brownish oily substance floated on the surface of the distillate. The entire acid liquid was made alkaline with sodium carbonate and shaken four times successively with ether. The ethereal liquid was washed with a little water four times and dried with anhydrous sodium sulfate. On evaporating off the solvent, there remained an exceedingly small amount of highly aromatic, semisolid substance of brown color. It gives no reaction of phenol and is insoluble in a cold solution of potassium hydroxide but readily dissolves on warming. After keeping in a vacuum over paraffin, it was analyzed:

$$
\begin{aligned}
& 0.0647 \mathrm{~g} \text {. gave } 0.1870 \mathrm{CO}_{2} \text { and } 0.0627 \mathrm{H}_{2} \mathrm{O} \ldots \ldots \ldots . \mathrm{C}=7_{8.83} \mathrm{H}=10.76 \\
& \mathrm{C}_{20} \mathrm{H}_{23} \mathrm{O}_{2} \text { requires..................... } \mathrm{C}=7_{78.86} \quad \mathrm{H}=10.60
\end{aligned}
$$

This substance, to which we assign the provisional formula $\mathrm{C}_{20} \mathrm{H}_{32} \mathrm{O}_{2}$, is evidently a lactone.

The alkaline solution, from which the lactone had been separated, was evaporated to a small bulk, strongly acidified with sulfuric acid and extracted several times with ether. The ethereal solution was washed four times with a little water, dried and evaporated. The slightly colored oily residue, thus obtained, was viscous in nature and possessed a pungent odor resembling that of acetic acid. It was difficultly soluble in water and crystallized at $\mathrm{II}^{\circ}$.

1 Two or three diterpenes, not included in this list, are mentioned in the formula register.-Epitor. 
䓂

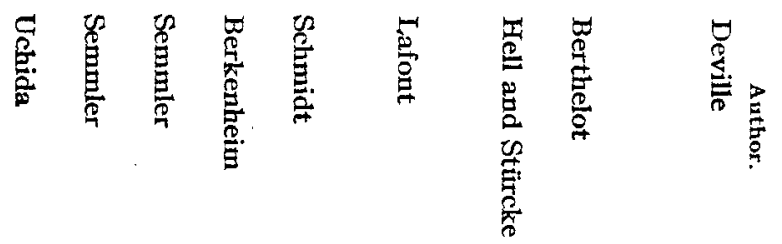

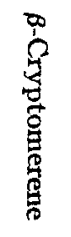

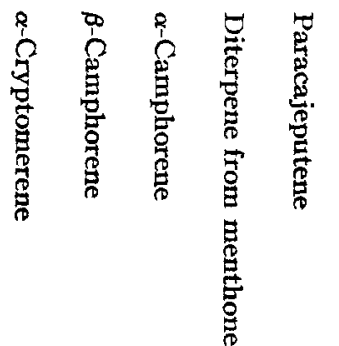

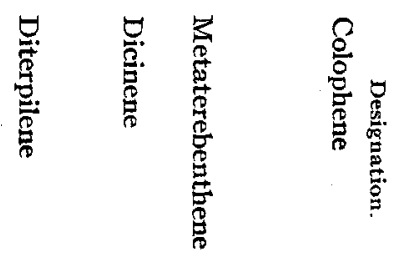

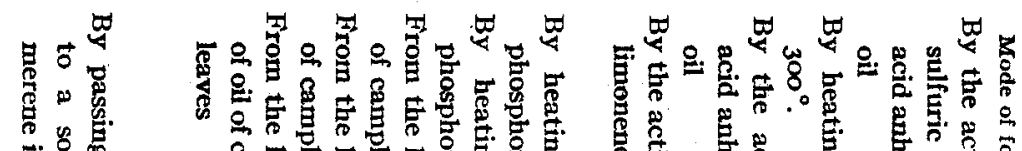

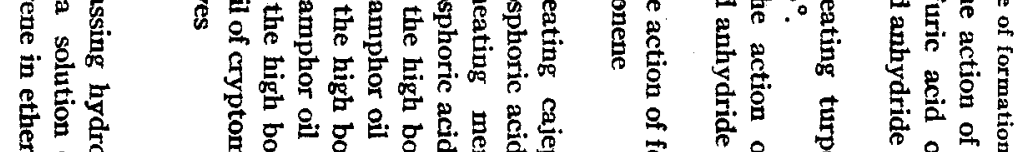

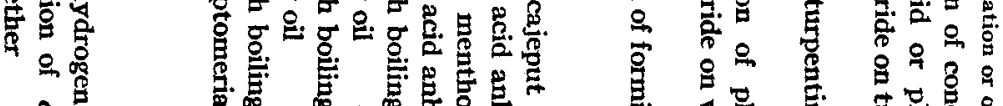

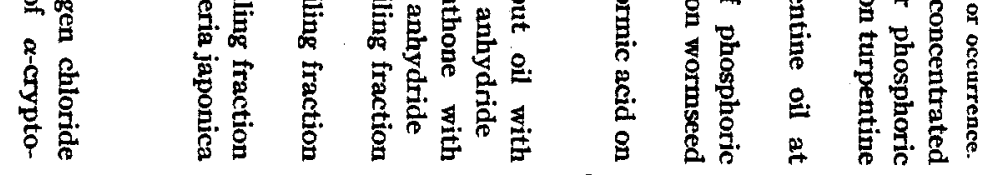

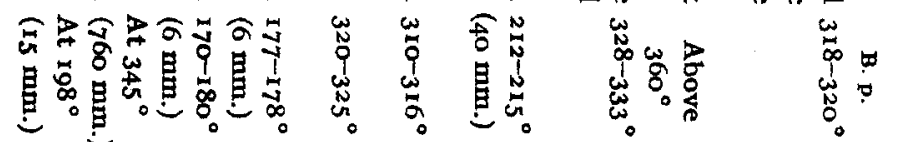

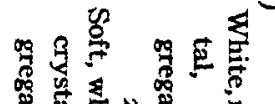

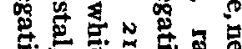

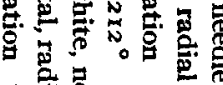
窟蒂

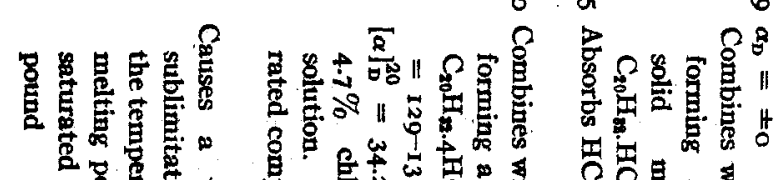
$\begin{array}{llllllll}0 & 0 & 0 & 0 & 0 & 0 \\ \dot{0} & \dot{0} & \dot{0} & \vdots & \dot{0} & \vdots & \dot{0} & \vdots \\ 0 & 0 & 0 & 0 & 0 & 0\end{array}$

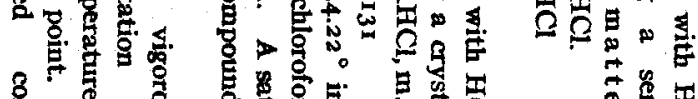

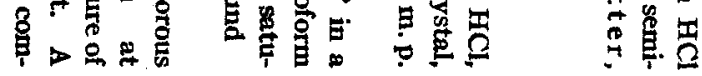

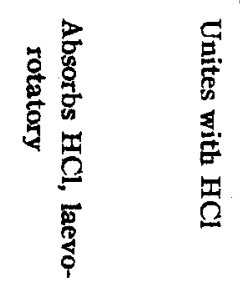


Titration of the Acid.-A decinormal alcoholic potash was run into a solution of the acid in the same solvent, phenolphthalein being used as indicator. $0.2736 \mathrm{~g}$. acid required for neutralization $104.8 \mathrm{mg}$. KOH. For a monobasic acid of the formula $\mathrm{C}_{8} \mathrm{H}_{16} \mathrm{O}_{2}, 106.5 \mathrm{~g}$. $\mathrm{KOH}$ would be required. The silver salt, prepared from the potassium salt, gave the following number on analysis:

$$
\begin{aligned}
& 0.1045 \mathrm{~g} . \text { gave on ignition } 0.0462 \mathrm{Ag} \ldots \ldots \ldots \ldots \mathrm{Ag}=44.21 \% \\
& \mathrm{C}_{8} \mathrm{H}_{18} \mathrm{O}_{2} \mathrm{Ag} \text { requires................... Ag }=43.16 \%
\end{aligned}
$$

The small amount of the acid did not permit further investigation but its general properties and the result of analysis served to confirm the acid to be caprylic acid. It may also be noted that the ester of this alcohol was present in relatively small amount in the oil and the greater part of the alcohol exists in the oil in a free state.

\section{Summary.}

From the preceding details it will be seen that this essential oil of Sugi (Cryptomeria japonica) leaves contains the following substances:

I. $d$ - $\alpha$-Pinene.

2. Dipentene.

3. An alcohol $\left(\mathrm{C}_{10} \mathrm{H}_{18} \mathrm{O}\right.$, b. p. $\left.=212-2 \mathrm{I}_{4}^{\circ}, d_{18}=0.94 \mathrm{I} 4, n_{\mathrm{D}}^{22.8}=1.4832\right)$.

4. Cadinene.

5. A sesquiterpene with two double linkings $\left(\mathrm{C}_{15} \mathrm{H}_{24}\right.$, b. p. $=266-268^{\circ}$, $d_{15}=0.9335, n_{\mathrm{D}}^{22.8}=1.504 \mathrm{I},[\alpha]_{\mathrm{D}}=+15.19^{\circ}$ in a $6.08 \%$ chloroform solution).

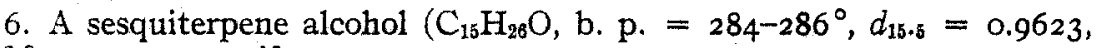
$n_{\mathrm{D}}^{22.8}=1.5048,[\alpha]_{\mathrm{D}}^{15}=+16.76^{\circ}$ in a $5 \%$ chloroform solution).

7. A new diterpene $\left(\mathrm{C}_{20} \mathrm{H}_{32}\right.$, b. p. $780=345^{\circ}$, b. p.15 $=198,[\alpha]_{\mathbf{D}}=$ $-34.22^{\circ}$ in a $4.67 \%$ chloroform solution) for which the author proposed the name " $\alpha$-Cryptomerene."

8. A lactone $\left(\mathrm{C}_{20} \mathrm{H}_{32} \mathrm{O}_{2}\right)$.

9. Caprylic acid in combination with the alcohol.

Io. Higher fatty acids in a free state.

I I. A blue oil, "Azulene."

The relative proportion of the above constituents is approximately as follows:

The terpenes, consisting chiefly of $d$ - $\alpha$-pinene with a small quantity of dipentene, represented $34 \%$. The amount of two sesquiterpenes was about $30 \%$, the sesquiterpene of the boiling point $266-268^{\circ}$ above mentioned more highly predominating than cadinene. The alcohol represented about $4.5 \%$, and was present partly in the uncombined state and partly as caprylic ester, the former highly predominating. " $\alpha$ Cryptomerene" represented about $18 \%$ of the oil. The amount of sesquiterpene alcohol was about $12 \%$, and finally the amounts of the 
lactone, the free fatty acids and a blue oil "Azulene" were exceedingly small.

Tokyo, JaPan.

[Contribution from the Department of Applied Chemistry, Engineerina COLLEGE, IMPERIAI UNIVERSITY OF JAPAN.]

ESSENTIAL OIL OF FORMOSAN HINOKI (Chamaecyparis obtusa, S. et Z.) WOOD.

BY So UchIDA.

Received December 8, 1915.

The Hinoki tree (Chamaecyparis obtusa, S. et Z.), which is extensively grown in Japan, furnishes a valuable timber wood of superior quality and is likewise prized for the manifold uses to which the wood is well adapted. In the mountain districts (5000-7000 ft.) of Formosa, Hinoki trees thrive most wonderfully, forming a splendid virgin forest. The present paper is concerned with the results obtained in experiments on the composition of Formosan Hinoki wood oil. A sample of the crude oil obtained by the dry distillation of wood was forwarded in I9I 2 from the Forest office of Arisan Mountains, Formosa. The yield of the crude oil was reported to be $2.4 \%$ of the wood. On examination of the sample, it was a reddish brown, mobile liquid possessing a woody and empyreumatic smell and contained some tarry matter.

Rectification of the Crude Oil.-A quantity of the crude oil weighing $780 \mathrm{~g}$. was first rectified by distillation with steam and $700 \mathrm{~g}$. of the rectified oil were obtained which amounted to $89.9 \%$ of the crude oil or $2.16 \%$ of the weight of wood. The quantity of the distilled water used in rectification was 81 . The oil thus obtained was mobile, lemon-yellow in color and possessed a Hinoki wood odor. To remove the pyrogenous acids which it still contained, it was subsequently treated with dilute sodium carbonate solution, washed with water and dried with anhydrous sodium sulfate. The oil, thus rectified, has a density $\mathrm{d}_{15.5}=0.882 \mathrm{I}$; the refractive index $n_{\mathrm{D}}^{18.5}=\mathrm{I} .4990$, and $[\alpha]_{\mathrm{D}}=+50.37^{\circ}$ in a $10 \%$ chloroform solution.

Fractional Distillation of the Oil.-A quantity of the rectified oil weighing $448 \mathrm{~g}$. was distilled fractionally under atmospheric pressure, and began to boil at $157^{\circ}$ and continued to distil until the temperature rose to $270^{\circ}$. It was resolved into the following three fractions, a reddish brown, resinous substance amounting to $\mathrm{I} .5 \%$ of the oil employed remaining in the distilling flask:

$$
\text { I, } 157-200^{\circ} \text {; II, } 200-240^{\circ} \text {; III, } 240-270^{\circ} \text {. }
$$

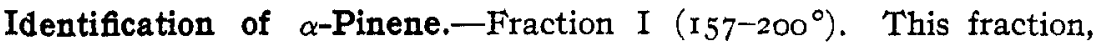
which was by far the largest obtained, representing $68.7 \%$ of the whole of the oil used, was mobile and almost colorless. When heated with metallic sodium, it was practically unacted on. The substance was, 